\title{
Tuning the Pore Size in Ionic Nanoparticle Networks
}

\author{
Marie-Alexandra Neouze Gauthey, ${ }^{1}$ Marco Litschauer, ${ }^{1}$ Michael Puchberger, ${ }^{1}$ \\ Martin Kronstein, ${ }^{1}$ and Herwig Peterlik ${ }^{2}$ \\ ${ }^{1}$ Vienna University of Technology, Institute of Materials Chemistry, 1060 Vienna, Austria \\ ${ }^{2}$ University of Vienna, Faculty of Physics, 1090 Vienna, Austria \\ Correspondence should be addressed to Marie-Alexandra Neouze Gauthey; maiaatneouze@hotmail.com
}

Received 11 January 2013; Accepted 1 February 2013

Academic Editor: Amir Kajbafvala

Copyright (C) 2013 Marie-Alexandra Neouze Gauthey et al. This is an open access article distributed under the Creative Commons Attribution License, which permits unrestricted use, distribution, and reproduction in any medium, provided the original work is properly cited.

\begin{abstract}
Highly promising hybrid materials consisting of silica, titania, or zirconia nanoparticles linked with ionic liquid-like imidazolium units have been developed. The nanoparticle networks are prepared by click-chemistry-like process through a nucleophilic substitution reaction. The type of metal oxide nanoparticles appears to play a key role regarding the pore size of the hybrid material.
\end{abstract}

\section{Introduction}

Recently the materials community is focusing on the development of specific materials based on assemblies of nanoparticles. These new materials aim at making use of nanoparticle collective properties. In this context, various synthetic pathways were proposed, such as template-assisted synthesis $[1,2]$, layer-by-layer deposition [3], or using covalent organic mediator [4-8]. These nanoparticle assemblies are already highly promising for numerous applications, like plasmonics, catalysis, or gas sorption/gas sequestration applications.

For catalysis and gas sorption/sequestration applications, the porosity of these materials is an important aspect $[9,10]$. Wacker et al. developed a purely inorganic porous nanoparticle assembly, by the bridging of magnetite nanoparticle with silica colloids, for catalytic applications [11], while Gao and coworkers prepared porous magnetite nanochain assemblies for water treatment [12].

However, for such applications like catalysis and gas separation, the use of hybrid inorganic-organic porous materials can be even more interesting, as the organic counterpart is able to interact with gas molecules or precursors. Thus, it was shown that the presence of ionic linker can enhance the adsorbent-adsorbate interactions through charge-induced forces [13]. In particular, ionic liquid-like linkers were pointed out to be extremely interesting [14-18]. More specifically, the high affinity of carbon dioxide for imidazolium moieties was evidenced $[8,19,20]$. For example, Lee et al. have reported the effective absorbtion of carbon dioxide over methane by copper imidazolium microporous frameworks [21]. This separation is enabled by the effects of both the metal site and the ionic imidazolium species.

In this context, we have already reported the synthesis of titania Ionic Nanoparticle Networks (INNs), where the titania nanoparticles are covalently linked by means of imidazolium bridges [22]. The titania INNs have shown to possess pores with a diameter centred on $2 \mathrm{~nm}$.

The present communication describes a new INN material based on zirconia nanoparticles and compares the porous characteristics of different INNs, with various metal oxide nanoparticles. In these materials, the liking imidazolium moieties are maintained in the network and thus remained accessible to adsorbed molecules.

\section{Experimental Section}

2.1. Chemicals. Chemicals unless otherwise stated were used without further purification. Titanium isopropoxide $\left(\mathrm{Ti}\left(\mathrm{O}^{\mathrm{i}} \mathrm{Pr}\right)_{4}\right)$, 1,3-dibromopropane, bromotrimethylsilane, potassium tert-butoxide, dimethylphosphite, 1-bromo-3chloropropane, sodiumhydride, triethylphosphit, dimethylformamide (DMF), tetrahydrofuran (THF), $\mathrm{Na}_{2} \mathrm{SO}_{4}, \mathrm{P}_{2} \mathrm{O}_{5}$, and zirconium oxychloride octahydrate $\left(\mathrm{ZrOCl}_{2} 8 \mathrm{H}_{2} \mathrm{O}\right)$ were obtained from Sigma-Aldrich, ammonia (32\%) and hydrochloric acid (37\%) from VWR, imidazole, sodium iodide, and tetraethylorthosilicate from Fluka, nitric acid 
(53\%), dichloromethane, and ethanol from Merck, acetone, chloroform, diethylether, ethanol, methanol, and toluene from Donau Chemie, and 3-chloropropyltrimethoxysilane (Si-Cl) from ABCR.

2.2. Measurements. Transmission Electron Microscopy (TEM) measurements: samples for transmission electron microscopy measurements were prepared by dispersing the particles in ethanol prior to deposition on a carbon-coated TEM $\mathrm{Cu}$ grid. TEM measurements were performed on a JEOL JEM-100CX (USTEM, Vienna University of Technology).

$\mathrm{X}$-ray powder diffraction (XRD) measurements were performed on a Philips X'Pert diffractometer using the $\mathrm{Cu}$ $\mathrm{K} \alpha$ radiation $(\lambda=1.542 \AA)$.

Small-angle X-ray scattering (SAXS) was performed using a rotating anode generator equipped with a pinhole camera (Nanostar from Bruker AXS, Karlsruhe, with $\mathrm{Cu} \mathrm{K} \alpha$ radiation from crossed Göbel mirrors). The X-ray patterns were recorded with an area detector (VANTEC 2000) and radially averaged to obtain the scattering intensity in dependence on the scattering vector $q=(4 \pi / \lambda) \sin \theta$, with $2 \theta$ being the scattering angle and $\lambda=0.1542 \mathrm{~nm}$ the X-ray wavelength.

Diffraction light scattering (DLS): for the measurement, the solid was dissolved in ethanol. The DLS experiments were carried out without previous sonication of the samples. The run time of the measurements was 10 seconds. Every size distribution curve was obtained by averaging 10 measurements. The apparatus is an ALV/CGS-3 compact goniometer system, equipped with an ALV/LSE-5003 light scattering electronics and multiple $\tau$ digital correlator and a $632,8 \mathrm{~nm}$ JDSU laser $1145 \mathrm{P}$.

$\mathrm{N}_{2}$ sorption isotherms were obtained from $\mathrm{N}_{2}$-adsorption/desorption experiments at $77 \mathrm{~K}$ using a Micrometrics ASAP 2020 analyzer. Specific surface areas were calculated from the BET equation, with the average pore diameter being evaluated by the $\mathrm{BJH}$ equation on the desorption branch of the isotherm. Before analysis, the samples were evacuated overnight at room temperature.

Fourier transform infrared (FT-IR) spectra: the products were pelletized in $\mathrm{KBr}$ before measurement. The spectrometer is a Bruker Tensor-27-DTGS equipped with an Interferometer RockSolid and a DigiTect detector system, highsensitivity DLATGS, using the OPUSTM software.

Nuclear Magnetic Resonance (NMR): solid-state NMR spectra were recorded on a Bruker AVANCE $300\left({ }^{1} \mathrm{H}\right.$ at $299.85 \mathrm{MHz}$ and ${ }^{15} \mathrm{~N}$ at $30.38 \mathrm{MHz}$ ) equipped with a $4 \mathrm{~mm}$ broadband MAS probe head. ${ }^{15} \mathrm{~N}$ spectra were recorded with ramped CP MAS experiments (Cross Polarization and Magic Angle Spinning). The sample holders were spun at $6 \mathrm{kHz}$ for the ${ }^{15} \mathrm{~N}$. Liquid-state NMR spectra were recorded on a Bruker AVANCE $250\left({ }^{1} \mathrm{H}\right.$ at $250.13 \mathrm{MHz},{ }^{13} \mathrm{C}$ at $62.90 \mathrm{MHz},{ }^{31} \mathrm{P}$ at 101.25 MHz) equipped with a $5 \mathrm{~mm}$ QNP probe head.

\subsection{Syntheses}

2.3.1. Modification of the Silica Nanoparticles with Si-Im or Si$\mathrm{Cl}$ and Formation of $\mathrm{SiO}_{2}-\mathrm{INN}$. The synthesis of $\mathrm{N}$-(trimethoxysilylpropyl)imidazole (Si-Im) as well as the synthesis of the silica nanoparticles were already reported [6]. Si-Im is colourless liquid.

${ }^{1} \mathrm{H} \mathrm{NMR}\left(250.13 \mathrm{MHz}, \mathrm{CDCl}_{3}\right): 0.54\left(\mathrm{t}, 2 \mathrm{H}, \mathrm{Si}-\mathrm{CH}_{2}\right), 1.83$ (q, $2 \mathrm{H}, \mathrm{N}-\mathrm{CH}_{2}-\mathrm{CH}_{2}$ ), $3.53\left(\mathrm{~s}, 9 \mathrm{H}, \mathrm{Si}-\mathrm{O}-\mathrm{CH}_{3}\right), 3.88(\mathrm{t}, 2 \mathrm{H}$, $\left.\mathrm{N}-\mathrm{CH}_{2}\right), 6.88(\mathrm{~s}, 1 \mathrm{H}, \mathrm{N}-\mathrm{CH}-\mathrm{CH}-\mathrm{N}), 7.01$ (s, 1H, N-CH$\mathrm{CH}-\mathrm{N}), 7.54$ (s, 1H, N-CH-N) ppm.

${ }^{13} \mathrm{C} \mathrm{NMR}\left(62.90 \mathrm{MHz}, \mathrm{CDCl}_{3}\right): 7.4\left(\mathrm{Si}-\mathrm{CH}_{2}\right), 25.1(\mathrm{~N}-$ $\left.\mathrm{CH}_{2}-\mathrm{CH}_{2}\right), 55.7\left(\mathrm{~N}-\mathrm{CH}_{2}\right), 56.2\left(\mathrm{Si}-\mathrm{O}-\mathrm{CH}_{3}\right), 120.7(\mathrm{~N}-\mathrm{CH}-$ $\mathrm{CH}-\mathrm{N}), 128.1(\mathrm{~N}-\mathrm{CH}-\mathrm{CH}-\mathrm{N}), 136.8(\mathrm{~N}-\mathrm{CH}-\mathrm{N})$ ppm.

$16 \mathrm{~mL}$ of a previously prepared silica nanoparticles suspension was transferred into a Schlenk tube and degassed in vacuum several minutes to remove excessive ammonia. Either $1.42 \mathrm{~g}$ ( $7.147 \mathrm{mmol})$ of 3-chloropropyltrimethoxysilane (Si-Cl) or $1.65 \mathrm{~g}$ (7.147 mmol) of $N$-(trimethoxysilylpropyl) imidazole (Si-Im) was added dropwise. The solutions were stirred in argon atmosphere at room temperature overnight.

The networking reaction $\left(\mathbf{S i O}_{2}\right.$ INN) was carried out in argon atmosphere. $5 \mathrm{~mL}$ suspension of silica nanoparticles modified with $N$-(trimethoxysilylpropyl)imidazole $\left(\mathrm{SiO}_{2}\right.$-Im $)$ and $5 \mathrm{~mL}$ suspension of silica nanoparticles modified with 3-chloropropyltrimethoxysilane $\left(\mathrm{SiO}_{2} \mathbf{C l}\right)$ were introduced in a $50 \mathrm{~mL}$ round bottom flask. Additionally $10 \mathrm{~mL}$ of dry methanol was added. The solution was refluxed over 2 days and finally the solvent was removed in vacuum (3 mbar). A translucent gel was obtained, washed with acetone, ethanol, and water, $20 \mathrm{~mL}$, respectively. The final product was dried in a desiccator over $\mathrm{P}_{2} \mathrm{O}_{5}$ in vacuum.

\subsubsection{Synthesis of P-Im or P-Cl: Synthesis of 3-Chloropropyl- phosphonic Acid $(\mathrm{P}-\mathrm{Cl})^{3}$}

Synthesis of Dimethyl-3-chloropropylphosphonate. $18 \mathrm{~g}$ $(160.41 \mathrm{mmol})$ potassium tert-butoxide was suspended in $150 \mathrm{~mL}$ THF. Afterwards, $22.01 \mathrm{~g}(200 \mathrm{mmol})$ dimethylphosphite was slowly added under vigorous stirring. After 2 hours of stirring, the whole suspension was slowly added to a stirred suspension of $47.23 \mathrm{~g}$ (300 mmol) 1-bromo-3-chloropropane in $120 \mathrm{~mL}$ THF in a $500 \mathrm{~mL}$ round bottom flask. A white suspension was formed immediately. The mixture was heated to reflux for 20 minutes. After cooling to room temperature, the formed precipitate, potassium bromide, was filtered off and washed twice with $100 \mathrm{~mL}$ diethylether. Then the solvents and by-products were removed under vacuum $\left(20 \mathrm{mbar}\right.$ at $\left.170^{\circ} \mathrm{C}\right)$. A slightly coloured liquid was obtained. Yield: $17.9 \mathrm{~g}(60 \%, 96.25 \mathrm{mmol})$.

${ }^{1} \mathrm{H}$ NMR (250 MHz, $\mathrm{CDCl}_{3}$ ): 1.82-1.92 (m, 2H, P- $\mathrm{CH}_{2}-$ $\left.\mathrm{CH}_{2}\right), 1.93-2.10\left(\mathrm{~m}, 2 \mathrm{H}, \mathrm{P}-\mathrm{CH}_{2}\right), 3.58\left(\mathrm{t}, 2 \mathrm{H}, \mathrm{Cl}-\mathrm{CH}_{2}\right), 3.72$ (d, 6H, P-O-CH ${ }_{3}$ ) ppm.

${ }^{31} \mathrm{P} \mathrm{NMR}\left(250 \mathrm{MHz} \mathrm{CDCl}_{3}\right.$ ): $45.99 \mathrm{ppm}$.

Synthesis of 3-Chloropropylphosphonic Acid. $6.169 \mathrm{~g}$ (33.07 $\mathrm{mmol}$ ) dimethyl-3-chloropropylphosphonate was mixed with $40 \mathrm{~mL}$ hydrochloric acid (37\%) and heated to reflux for 24 hours. Afterwards, the solvent was removed under reduced pressure, and the residues of water were removed through azeotropic distillation by adding $20 \mathrm{~mL}$ of toluene. The yellowish liquid residue was crystallized from $50 \mathrm{~mL}$ chloroform and filtered. The colourless crystalline product 
was dried in a desiccator over $\mathrm{P}_{2} \mathrm{O}_{5}$ under vacuum. Yield: $3.73 \mathrm{~g}(70 \%, 23.53 \mathrm{mmol})$.

$\mathbf{P}-\mathrm{Cl}$ is colourless crystalline product.

${ }^{1} \mathrm{H}$ NMR (250 MHz, DMSO-d6): 1.63-1.69 (m, 2H, P$\left.\mathrm{CH}_{2}-\mathrm{CH}_{2}\right), 1.83-1.90\left(\mathrm{~m}, 2 \mathrm{H}, \mathrm{P}-\mathrm{CH}_{2}\right), 3.67\left(\mathrm{t}, 2 \mathrm{H}, \mathrm{Cl}-\mathrm{CH}_{2}\right)$, 7.29 (s, 2H, P-OH) ppm.

${ }^{31} \mathrm{P}$ NMR (101.25 MHz, DMSO-d6): 37.85 ppm.

${ }^{13} \mathrm{C}-\mathrm{NMR}$ (62.90 MHz, DMSO-d6): $24.2\left(\mathrm{P}-\mathrm{CH}_{2}-\mathrm{CH}_{2}\right)$, $26.4\left(\mathrm{P}-\mathrm{CH}_{2}\right), 46.1\left(\mathrm{Cl}-\mathrm{CH}_{2}\right) \mathrm{ppm}$.

Synthesis of N-Imidazolylpropylphosphonic Acid (PIm) $)^{3}$ : Synthesis of Diethyl-3-Bromopropylphosphonate. $30 \mathrm{~g}$ (180.55 mmol) triethylphosphite and $150 \mathrm{~g}$ (722.20 mmol) 1,3dibromopropane were heated under vigorous stirring to $160^{\circ} \mathrm{C}$ for 30 minutes. Unreacted 1,3-dibromopropane was removed under reduced pressure and diethyl-3-bromopropylphosphonate distilled under vacuum $\left(2 \mathrm{mbar}\right.$ at $\left.165^{\circ} \mathrm{C}\right)$. A colorless liquid was obtained. Yield: $23.45 \mathrm{~g}$ (50\%, $90.5 \mathrm{mmol})$.

${ }^{1} \mathrm{H}$ NMR $\left(250 \mathrm{MHz}, \mathrm{CDCl}_{3}\right): 1.20\left(\mathrm{t}, 6 \mathrm{H}, \mathrm{P}-\mathrm{O}-\mathrm{CH}_{2}-\right.$ $\left.\mathrm{CH}_{3}\right), 1.80\left(\mathrm{~m}, 2 \mathrm{H}, \mathrm{P}-\mathrm{CH}_{2}-\mathrm{CH}_{2}\right), 1.99\left(\mathrm{~m}, 2 \mathrm{H}, \mathrm{Br}-\mathrm{CH}_{2}\right), 3.35$ (t, $\left.2 \mathrm{H}, \mathrm{P}-\mathrm{CH}_{2}\right), 3.97\left(\mathrm{~m}, 4 \mathrm{H}, \mathrm{P}-\mathrm{O}-\mathrm{CH}_{2}\right) \mathrm{ppm}$.

${ }^{31} \mathrm{P} \mathrm{NMR}\left(250 \mathrm{MHz}, \mathrm{CDCl}_{3}\right): 30.48 \mathrm{ppm}$.

${ }^{13} \mathrm{CNMR}\left(250 \mathrm{MHz}, \mathrm{CDCl}_{3}\right): 16.3\left(\mathrm{P}-\mathrm{O}-\mathrm{CH}_{2}-\mathrm{CH}_{3}\right), 23.1$ $\left(\mathrm{P}-\mathrm{CH}_{2}-\mathrm{CH}_{2}\right), 25.8\left(\mathrm{P}-\mathrm{CH}_{2}\right), 33.5\left(\mathrm{Br}-\mathrm{CH}_{2}\right), 61.5(\mathrm{P}-\mathrm{O}-$ $\mathrm{CH}_{2}-\mathrm{CH}_{3}$ ) ppm.

Synthesis of Sodium Imidazolide. Under argon, 1,2 g (50 $\mathrm{mmol}$ ) sodiumhydride was suspended in $150 \mathrm{~mL}$ dry THF. This suspension was cooled to $4^{\circ} \mathrm{C}$ with an ice bath, and $3.404 \mathrm{~g}(50 \mathrm{mmol})$ imidazole was added over a period of 30 minutes. The suspension was further stirred for 2 hours until no evolution of hydrogen is visible. Afterwards, the white product was filtered off and dried in a desiccator over $\mathrm{P}_{2} \mathrm{O}_{5}$ under vacuum. Yield: $4.41 \mathrm{~g}(98 \%, 49 \mathrm{mmol})$.

Synthesis of Dimethyl-N-Imidazolpropylphosphonate. Under argon in an $25 \mathrm{~mL}$ round bottom flask, $0.9 \mathrm{~g}(10 \mathrm{mmol})$ of sodium imidazolide was dissolved in $5 \mathrm{~mL}$ dry DMF. The solution was cooled to $4^{\circ} \mathrm{C}$ with an ice bath, and $2.59 \mathrm{~g}$ (10 mmol) diethyl-3-bromopropylphosphonate was added at once. Afterwards, the ice bath is removed and the suspension is heated to $55^{\circ} \mathrm{C}$ for 8 hours under vigorous stirring. The solvent was removed under reduced pressure at $40^{\circ} \mathrm{C}$. The liquid residue was extracted with chloroform and water, 3 times, with $10 \mathrm{~mL}$, respectively. The collected organic phases were dried over $\mathrm{MgSO}_{4}$ and the solvent evaporated under vacuum. A colorless liquid was obtained. Yield: $0.78 \mathrm{~g}(26 \%$, $3.16 \mathrm{mmol})$.

${ }^{1} \mathrm{H}$ NMR $\left(250 \mathrm{MHz}, \mathrm{CDCl}_{3}\right): 1.26\left(\mathrm{t}, 6 \mathrm{H}, \mathrm{P}-\mathrm{O}-\mathrm{CH}_{2}-\right.$ $\left.\mathrm{CH}_{3}\right), 1.61\left(\mathrm{~m}, 2 \mathrm{H}, \mathrm{P}-\mathrm{CH}_{2}-\mathrm{CH}_{2}\right), 1.99\left(\mathrm{~m}, 2 \mathrm{H}, \mathrm{P}-\mathrm{CH}_{2}-\mathrm{CH}_{2}-\right.$ $\left.\mathrm{CH}_{2}\right), 3.98\left(\mathrm{~m}, 4 \mathrm{H}, \mathrm{P}-\mathrm{CH}_{2}, \mathrm{P}-\mathrm{O}-\mathrm{CH}_{2}\right), 6.91(\mathrm{~d}, 2 \mathrm{H}, \mathrm{N}-\mathrm{CH}-$ $\mathrm{CH}-\mathrm{N}), 7.43(\mathrm{~s}, 1 \mathrm{H}, \mathrm{N}-\mathrm{CH}-\mathrm{N}) \mathrm{ppm}$.

${ }^{31} \mathrm{P}$ NMR $\left(250 \mathrm{MHz}, \mathrm{CDCl}_{3}\right): 30.21 \mathrm{ppm}$.

${ }^{13} \mathrm{CNMR}\left(250 \mathrm{MHz}, \mathrm{CDCl}_{3}\right): 16.3\left(\mathrm{P}-\mathrm{O}-\mathrm{CH}_{2}-\mathrm{CH}_{3}\right), 21.1$ $\left(\mathrm{P}-\mathrm{CH}_{2}-\mathrm{CH}_{2}\right), 24.4\left(\mathrm{P}-\mathrm{CH}_{2}\right), 46.7\left(\mathrm{~N}-\mathrm{CH}_{2}\right), 61.7(\mathrm{P}-\mathrm{O}-$ $\left.\mathrm{CH}_{2}-\mathrm{CH}_{3}\right), 118.7(\mathrm{~N}-\mathrm{CH}-\mathrm{CH}-\mathrm{N}), 129.5(\mathrm{~N}-\mathrm{CH}-\mathrm{CH}-\mathrm{N})$, $137.1(\mathrm{~N}-\mathrm{CH}-\mathrm{N}) \mathrm{ppm}$.
Synthesis of N-Imidazolylpropylphosphonic Acid. Under argon in a $10 \mathrm{~mL}$ round bottom flask, $0.43 \mathrm{~g}(1,75 \mathrm{mmol})$ of dimethyl-N-imidazolpropylphosphonate was dissolved in $5 \mathrm{~mL}$ dry dichloromethane and stirred for 5 minutes. Afterwards, $0.80 \mathrm{~g}(5.24 \mathrm{mmol})$ bromotrimethylsilane was added and stirred for 24 hours. Then the solvent was removed under reduced pressure and the brownish viscous liquid was dissolved in $5 \mathrm{~mL}$ dry methanol. Afterwards, the excessive methanol was removed under reduced pressure. P-Im is a viscous brown liquid. Yield: $0.213 \mathrm{~g}(64 \%, 1.12 \mathrm{mmol})$.

${ }^{1} \mathrm{H}$ NMR $\left(250.13 \mathrm{MHz}, \mathrm{D}_{2} \mathrm{O}\right): 1.58\left(\mathrm{~m}, 2 \mathrm{H}, \mathrm{P}-\mathrm{CH}_{2}-\mathrm{CH}_{2}\right)$, $1.98\left(\mathrm{~m}, 2 \mathrm{H}, \mathrm{P}-\mathrm{CH}_{2}-\mathrm{CH}_{2}-\mathrm{CH}_{2}\right), 4.20\left(\mathrm{t}, 2 \mathrm{H}, \mathrm{P}-\mathrm{CH}_{2}\right), 7.38$ (d, $\left.2 \mathrm{H}, \mathrm{P}-\mathrm{CH}_{2}, \mathrm{~N}-\mathrm{CH}-\mathrm{CH}-\mathrm{N}\right), 8.63(\mathrm{~s}, 1 \mathrm{H}, \mathrm{N}-\mathrm{CH}-\mathrm{N}) \mathrm{ppm}$.

${ }^{31} \mathrm{P}$ NMR $\left(101.25 \mathrm{MHz}, \mathrm{D}_{2} \mathrm{O}\right): 27.19 \mathrm{ppm}$.

${ }^{13} \mathrm{C}$ NMR $\left(62.90 \mathrm{MHz}, \mathrm{D}_{2} \mathrm{O}\right): 22.2\left(\mathrm{P}-\mathrm{CH}_{2}-\mathrm{CH}_{2}\right), 24.3$ $\left(\mathrm{P}-\mathrm{CH}_{2}\right), 49.4\left(\mathrm{~N}-\mathrm{CH}_{2}\right), 119.8(\mathrm{~N}-\mathrm{CH}-\mathrm{CH}-\mathrm{N}), 121.9(\mathrm{~N}-$ $\mathrm{CH}-\mathrm{CH}-\mathrm{N}), 135.5(\mathrm{~N}-\mathrm{CH}-\mathrm{N}) \mathrm{ppm}$.

Synthesis of the Zirconia Nanoparticles and Modification with P-Im or P-Cl: Formation of $\mathrm{TiO}_{2}$ INN. Synthesis of Titania Nanoparticles. $10 \mathrm{~mL}(33.96 \mathrm{mmol})$ of $\mathrm{Ti}\left(\mathrm{O}^{\mathrm{i}} \mathrm{Pr}\right)_{4}$ was dissolved in $25 \mathrm{~mL}$ dry ethanol. This mixture was added dropwise under vigorous stirring to $250 \mathrm{~mL}$ water and adjusted to a $\mathrm{pH}$ of 1.7 with $1 \mathrm{~mL}$ nitric acid (53\%). During the addition, the reaction mixture was cooled to $4^{\circ} \mathrm{C}$ using an ice bath. After complete addition the ice bath was removed and the mixture stirred for 3 days at room temperature. Then, the solvent was removed under reduced pressure and the white crystalline product was dried in a desiccator over $\mathrm{P}_{2} \mathrm{O}_{5}$ under vacuum.

Formation of $\mathrm{TiO}_{2} I N N$. $1 \mathrm{~g}$ of previously synthesised $\mathrm{TiO}_{2}$ nanoparticles was dispersed in $50 \mathrm{~mL}$ water. To this suspension, either $0.244 \mathrm{~g}(1.54 \mathrm{mmol})$ of 3-chloropropylphosphonic acid $\left(\mathrm{TiO}_{2-} \mathrm{Cl}\right)$ or $0.293 \mathrm{~g}(1.54 \mathrm{mmol})$ of $\mathrm{N}$-imidazolylpropylphosphonic acid $\left(\mathrm{TiO}_{2}\right.$-Im), dissolved in $100 \mathrm{~mL}$ distilled water, respectively, was added. The white suspensions were stirred at room temperature for 24 hours. For analysis, the modified particles were isolated via centrifugation, washed several times with ethanol and water, and finally dried in a desiccator over $\mathrm{P}_{2} \mathrm{O}_{5}$ under vacuum. The networking nucleophilic substitution reaction $\left(\mathrm{TiO}_{2}\right.$ INN) was carried out by transferring $75 \mathrm{~mL}$ of the modified particles suspensions, $\mathrm{TiO}_{2-} \mathbf{C l}$ and $\mathrm{TiO}_{2}-\mathrm{Im}$, to a $250 \mathrm{~mL}$ round bottom flask and refluxed for 24 hours. Afterwards, the connected particles were centrifuged, washed two times with ethanol, and finally dried a desiccator over $\mathrm{P}_{2} \mathrm{O}_{5}$ in vacuum.

Synthesis of the Zirconia Nanoparticles and Modification with P-Im or P-Cl: Formation of $\mathrm{ZrO}_{2} I N N$. $\mathrm{ZrO}_{2}$ nanoparticles were synthesized by heating $20 \mathrm{~mL}$ of an aqueous 4 molar solution of $\mathrm{ZrOCl}_{2} 8 \mathrm{H}_{2} \mathrm{O}(80 \mathrm{mmol})$ to $200^{\circ} \mathrm{C}$ for 72 hours in a stainless-steel autoclave with a PTFE inlay. The particles were collected through precipitation with acetone and centrifugation. Afterwards, the nanoparticles were washed 3 times with ethanol and acetone, $20 \mathrm{~mL}$, respectively. Finally, the crystalline, white powder was dried in a desiccator over $\mathrm{P}_{2} \mathrm{O}_{5}$ under vacuum.

For surface modification, $0.5 \mathrm{~g}$ of $\mathrm{ZrO}_{2}$ nanoparticles was dispersed in $50 \mathrm{~mL}$ water. To this suspension either $80 \mathrm{mg}$ 


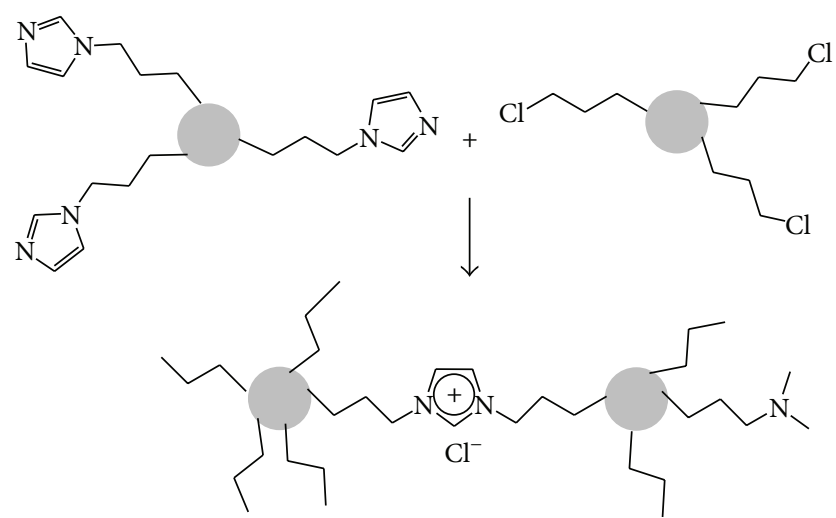

Scheme 1: The 3-dimaensional networking of nanoparticles by means of nucleophilic substitution to form INN hybrid material.

$(0.5 \mathrm{mmol})$ of 3-chloropropylphosphonic acid $\left(\mathrm{ZrO}_{2} \mathbf{C l}\right)$ or $95 \mathrm{mg}(0.5 \mathrm{mmol})$ of $\mathrm{N}$-imidazolylpropylphosphonic acid $\left(\mathbf{Z r O}_{2}\right.$ Im), dissolved in $50 \mathrm{~mL}$ distilled water, respectively, was added. The white suspensions were stirred at room temperature for 24 hours. For analysis, the modified particles were isolated via centrifugation, washed several times with water, ethanol, and acetone, and finally dried in a desiccator over $\mathrm{P}_{2} \mathrm{O}_{5}$ in vacuum. The networking nucleophilic substitution reaction $\left(\mathrm{ZrO}_{2}\right.$ INN) was carried out by transferring the two differently modified zirconia nanoparticle suspensions to a $250 \mathrm{~mL}$ round bottom flask and refluxed for 24 hours. Afterwards, the connected particles were centrifuged, washed two times with ethanol, and finally dried a desiccator over $\mathrm{P}_{2} \mathrm{O}_{5}$ in vacuum.

\section{Results and Discussion}

The various INN materials were prepared by reacting imidazole-modified nanoparticle with chloroalkyl-modified nanoparticles (Scheme 1) $[6,7]$.

The modified nanoparticles were on the one hand silica, for which the anchoring group was a functional trimethoxysilane, and on the other hand titania or zirconia, for which the anchoring group was a functional phosphonic acid [23]. The spherical silica and titania nanoparticles have a main diameter of $15 \mathrm{~nm}$ and $4 \mathrm{~nm}$, respectively (see Supplementary Information in the supplementary material available online at http://dx.doi.org/10.1155/2013/682945). The zirconia nanoparticles are $100 \%$ made of the monoclinic baddeleyite phase as verified with powder X-ray diffraction (bars: JCPDS no. 01-0750 for baddeleyite in Figure 1). The monoclinic zirconia nanoparticles are not spherical but elongated; from the DLS and XRD, their spherical equivalent diameter can be estimated to be $6 \mathrm{~nm}$ (Figure 1).

The anchoring of the functional groups onto the surface of the nanoparticles can be verified by ${ }^{29} \mathrm{Si} \mathrm{NMR}$, for the alkoxysilane onto silica [6]. The anchoring of functionalized phosphonic acid onto titania or zirconia surface was verified by FTIR (see Supplementary Information). The band of the $\mathrm{PO}_{3}$ environment at $950 \mathrm{~cm}^{-1}$ is shifted to $1030 \mathrm{~cm}^{-1}$ after anchoring, while the strength of the phosphorous-oxygen bonds is almost lowering due to the formation of titanium/zirconium oxygen bonds. In the same time, the bands at $770 \mathrm{~cm}^{-1}$ and $1150 \mathrm{~cm}^{-1}$ characteristic of the $\mathrm{P}-\mathrm{OH}$ and $\mathrm{P}=\mathrm{O}$ bonds, respectively, are disappearing due to the formation of the P-O-Ti liaisons. However in the case of $\mathbf{Z r O}_{2}$ Im and $\mathrm{ZrO}_{2} \mathbf{C l}$, the band at $750 \mathrm{~cm}^{-1}$ is hidden by the strong absorption band for the $\mathrm{Zr}-\mathrm{O}-\mathrm{Zr}$ bonds.

The functional groups, imidazole and chloroalkyl, at the surface of the nanoparticles are reacting with each other in a nucleophilic substitution reaction. The organic bridging molecule formed between two nanoparticles is an imidazolium chloride unit, as described in Scheme 1. This reaction occurs at low temperature (under $70^{\circ} \mathrm{C}$ ) in environmental friendly solvent (methanol or ethanol) and without formation of side-product. Thus, the reaction can be considered as a click-chemistry-like reaction.

The INN hybrid materials formation obtained from imidazole and chloroalkyl anchored on silica nanoparticles $\left(\mathbf{S i O}_{2} \mathbf{I N N}\right)$ or titania nanoparticles $\left(\mathbf{T i O}_{2} \mathbf{I N N}\right)$ were characterized in previous works by means of ${ }^{15} \mathrm{~N}$ NMR spectroscopy and/or anion exchange experiments [22, 24].

The formation of the zirconia nanoparticle network $\left(\mathrm{ZrO}_{2}\right.$ INN) by reaction of imidazole with chloropropyl functional groups anchored on zirconia nanoparticles was verified by anion metathesis. The metathesis reaction is obtained by reaction with sodium tetrafluoroborate in an acetone suspension of the INN. During the metathesis, the chloride imidazolium counter anion is exchanged by the tetrafluoroborate, leading to the formation of sodium chloride as side-product. After filtration of the hybrid material, as sodium chloride is not soluble in acetone, the presence of sodium chloride could be evidenced by X-ray diffraction (Figure 2, bars). The reflections at values of $2 \theta$ of $32^{\circ}, 46^{\circ}$, and $57^{\circ}$ are characteristic for $\mathrm{NaCl}$ (while the other reflections on the pattern can be assigned to $\mathrm{NaCl}$ but also to the excess of $\mathrm{NaBF}_{4}$ used in excess for the metathesis reaction). The formation of sodium chloride is the proof that anionic chloride was present in the hybrid material. Indeed, if no reaction occurred, only covalent chlorine species would be present. Such covalently bonded chlorine atoms cannot be exchanged by anion metathesis. Thus, the anion metathesis reaction indicates clearly that the imidazolium formation took place.

In addition to the anion metathesis, solid-state nuclear magnetic resonance of ${ }^{15} \mathrm{~N}$ was performed on the hybrid material $\mathbf{Z r O}_{2}$ INN. Despite performing the experiment under cross-polarization, the signal to noise ratio of the spectrum is quite poor due to three effects. The first two effects are the low gyromagnetic constant of the ${ }^{15} \mathrm{~N}(-2.7126 \times$ $\left.10^{7} \mathrm{rad} \cdot \mathrm{T}^{-1} \cdot \mathrm{s}^{-1}\right)$ and the very low natural abundancy of the isotope $(0,368 \%)$ [25]. The first aspect inducing a low signal to noise ratio is the low amount of nitrogen atoms in the sample: 2 nitrogen atoms per imidazolium chain in a material containing only $10 \mathrm{wt} \%$ organic (see Supplementary Information). Nevertheless, a clear peak can be observed at a chemical shift of 142 ppm in Figure 2. Reference experiments have shown that the reaction of imidazole to imidazolium results in a slight but characteristic shift of the nitrogen peak in the ${ }^{15} \mathrm{~N}$ NMR spectrum, from $133 \mathrm{ppm}$ to $142 \mathrm{ppm}$ [22]. 


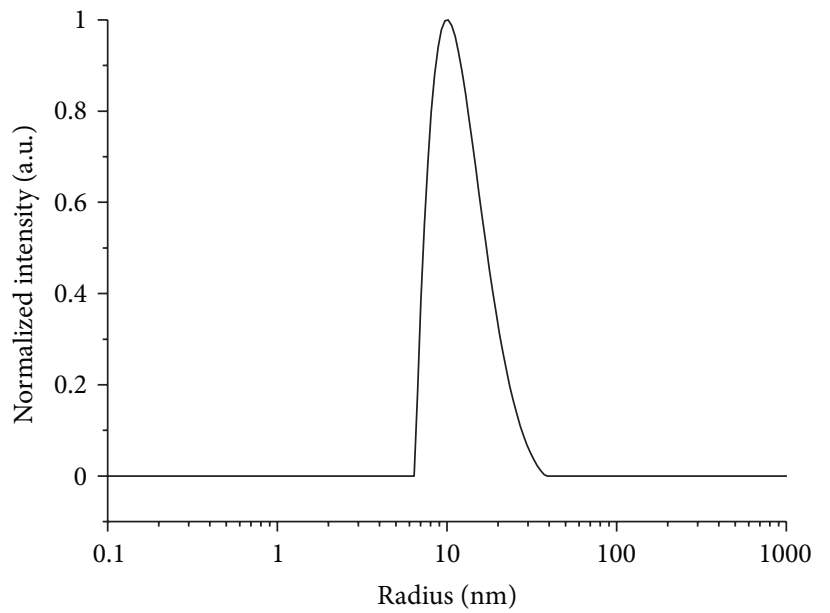

(a)

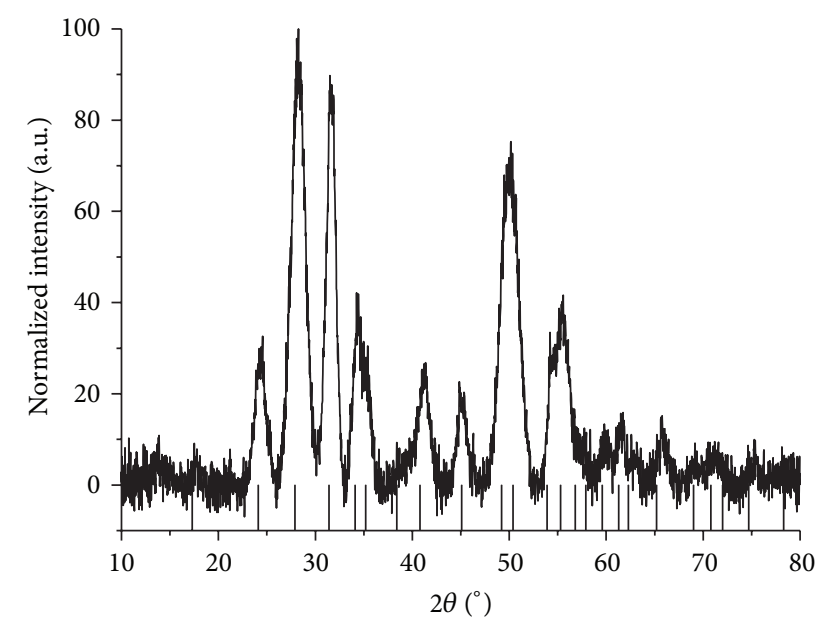

(b)

FIGURE 1: (a) DLS and (b) XRD patterns of the nonmodified zirconia nanoparticles.

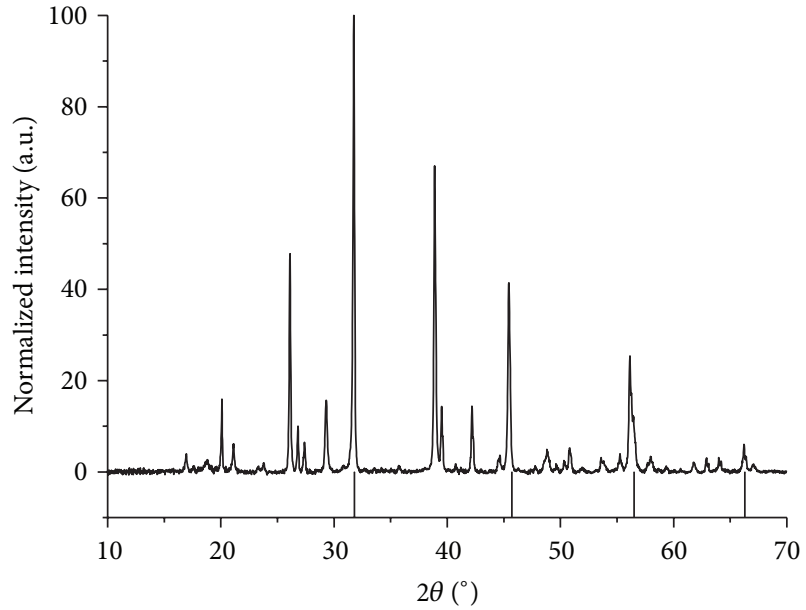

(a)

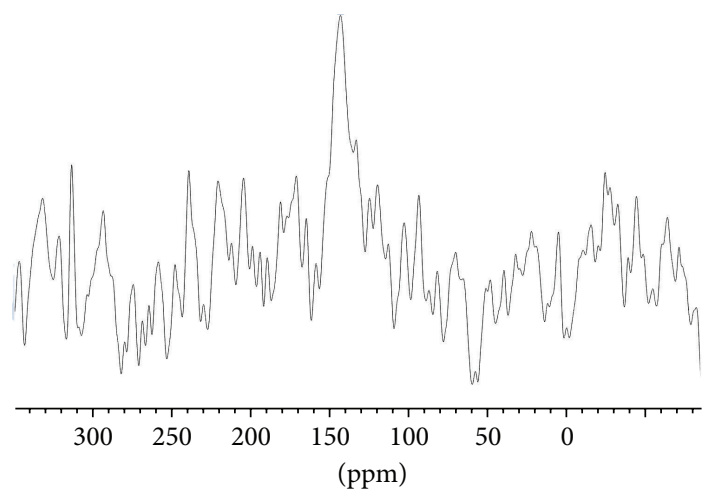

(b)

FIGURE 2: (a) XRD diffractogram of the anion exchange washing phase of $\mathbf{Z r O}_{2}$ INN (bars: JCPDS no. $74-0199$ for NaCl) and (b) CP MAS ${ }^{15} \mathrm{~N} \mathrm{NMR}$ of $\mathrm{ZrO}_{2}$ INN.

Thus, the peak observed at $142 \mathrm{ppm}$ for $\mathbf{Z r O}_{2}$ INN is the signature for the formation of an imidazolium species.

SAXS investigations could allow verifying the presence of nonagglomerated nanoparticles within the INN materials, as also discussed in the works of Feichtenschlager et al. and Pabisch et al. [26, 27]. Indeed, differences in the scattering intensities can be observed corresponding to the typical size and distance of single nanoparticles present in the hybrid material, at about $q=0.4 \mathrm{~nm}^{-1}$ for silica, $2 \mathrm{~nm}^{-1}$ for titania, and $1.0 \mathrm{~nm}^{-1}$ for zirconia (arrows on Figure 3). These peaks correspond in real space in a first approximation to a typical size of about $15 \mathrm{~nm}, 4 \mathrm{~nm}$, and $6 \mathrm{~nm}$ for $\mathrm{SiO}_{2}, \mathrm{TiO}_{2}$, and $\mathrm{ZrO}_{2}$, respectively. To be more precise, the scattering curves were fitted by a formal factorization with a mean form factor and an effective structure factor $[27,28]$. As form factor we used the unified function from Beaucage $[29,30]$ and as structure a hard sphere model [31]. These fits give a typical radius of gyration $r_{\mathrm{g}}$ of the particles, from which the equivalent spherical diameter $d_{\mathrm{p}}$ is obtained by $d_{\mathrm{p}}=2 r_{\mathrm{g}}$ Sqrt (5/3), a typical distance $D$ (twice the hard sphere radius $r_{\mathrm{HS}}$ ), and a packing density (the hard sphere volume factor $\eta$ ). At large scattering vectors, at $q>10 \mathrm{~nm}^{-1}$, the scattering peaks are corresponding either to amorphous silica, crystalline titania, or crystalline zirconia.

The porous characteristics of the three INN materials were measured by means of nitrogen sorption at $77 \mathrm{~K}$ after degassing in vacuum overnight at $75^{\circ} \mathrm{C}$ (Figure 4). The three materials present very different profiles.

The isotherm of $\mathrm{SiO}_{2}$ INN is a type II isotherm [32] characteristic for macroporous materials (Figure 3 top). The calculated BET surface area is very low, around $5( \pm 1) \mathrm{m}^{2} \cdot \mathrm{g}^{-1}$, which is consistent with the presence of macropores. The high 


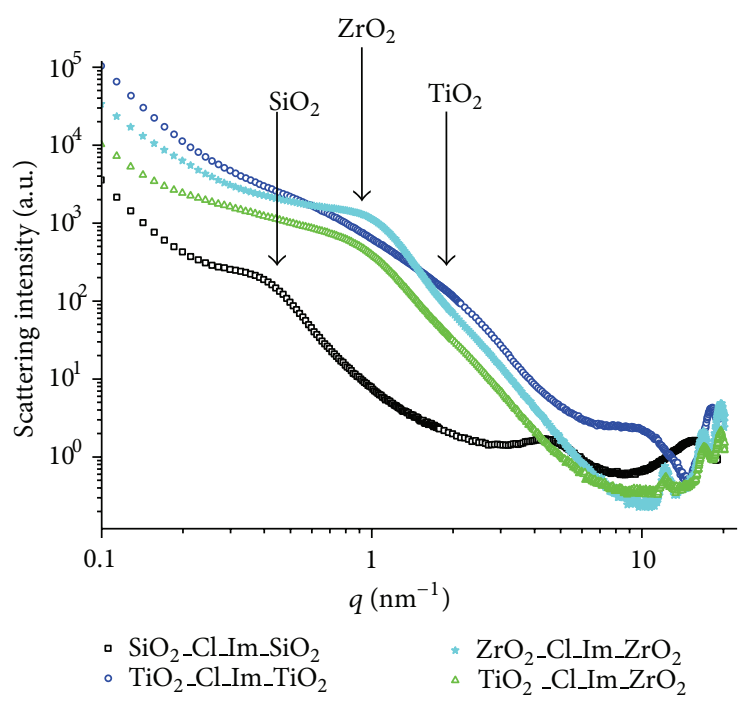

FIGURE 3: SAXS curves for various INNs (black squares for $\mathrm{SiO}_{2}$ INN, blue triangles for $\mathrm{TiO}_{2 \_} \mathrm{INN}$, and green stars for $\mathrm{ZrO}_{2}$ INN).

uncertainty on the surface area is due to the fact that the nitrogen sorption experiments are not suited for the determination of specific surface areas for macroporous materials and in consequence underestimate the values. The graph of the $\mathrm{BJH}$ method plotted for the desorption branch (Figure 4(b)) confirmed the presence of large pores, macropores, from around $20 \mathrm{~nm}$ diameter and broadly distributed toward larger pores.

The $\mathrm{TiO}_{2}$ INN in contrary shows a type $\mathrm{I}$ isotherm (Figure 3 top) [32], classical for microporous structures, with pore diameters centred on $2 \mathrm{~nm}$ and distributed toward smaller pores (Figure $4(\mathrm{~b})$ ). For this $\mathrm{TiO}_{2}$ INN hybrid material, the BET-specific surface area of the material reaches $205( \pm 5) \mathrm{m}^{2} \cdot \mathrm{g}^{-1}$. A relatively high specific surface area is characteristic of microporous materials.

The hybrid material $\mathbf{Z r O}_{2}$ INN represents an intermediary case. Here the nitrogen sorption isotherm (Figure 4(a)) is of type IV. This type IV isotherm corresponds to mesoporous materials. A BET-specific surface area of $90( \pm 4) \mathrm{m}^{2} \cdot \mathrm{g}^{-1}$ was estimated. The $\mathrm{BJH}$ plotted for the desorption branch (Figure 4(b)) indicated the presence of mesopores centred on $4 \mathrm{~nm}$ with a quite narrow distribution.

The INNs were also observed through transmission electronic microscopy. The TEM images are presented in Figure 5. The size and shape of the nanoparticles can be observed in the micrographs. However, the organic link cannot be distinguished. In the TEM micrographs, the pores which were characterized by nitrogen sorption experiments cannot be distinguished from defects in the network. Moreover, in the case of $\mathrm{TiO}_{2} \mathrm{INN}$, the pores are of around $2 \mathrm{~nm}$ and thus can hardly be observed by TEM.

We interpret the difference in the pore sizes as a consequence of the nanoparticle size or shape and the derived nanoparticle curvature. The silica nanoparticles in $\mathrm{SiO}_{2}$ INN are relatively large: a fit of the SAXS intensities gave a size

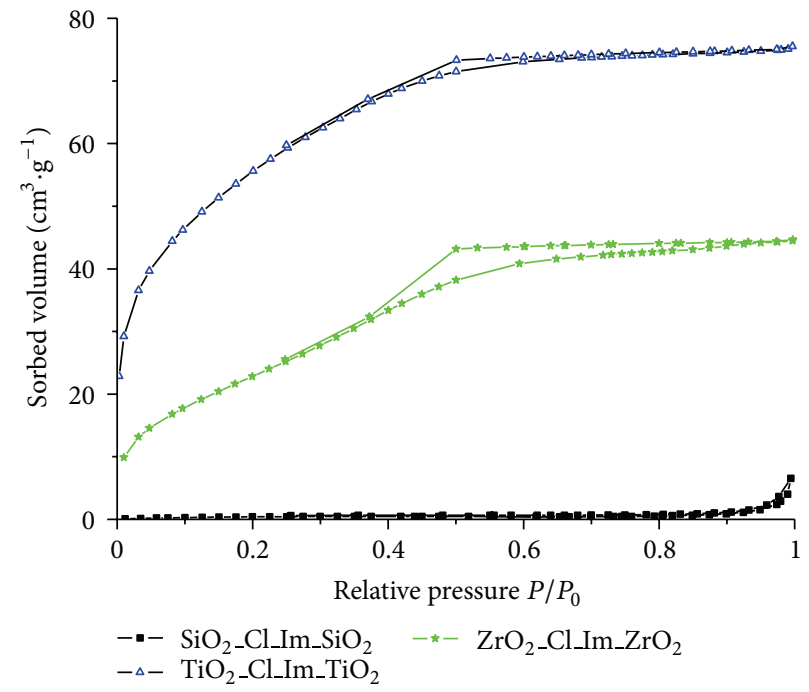

(a)

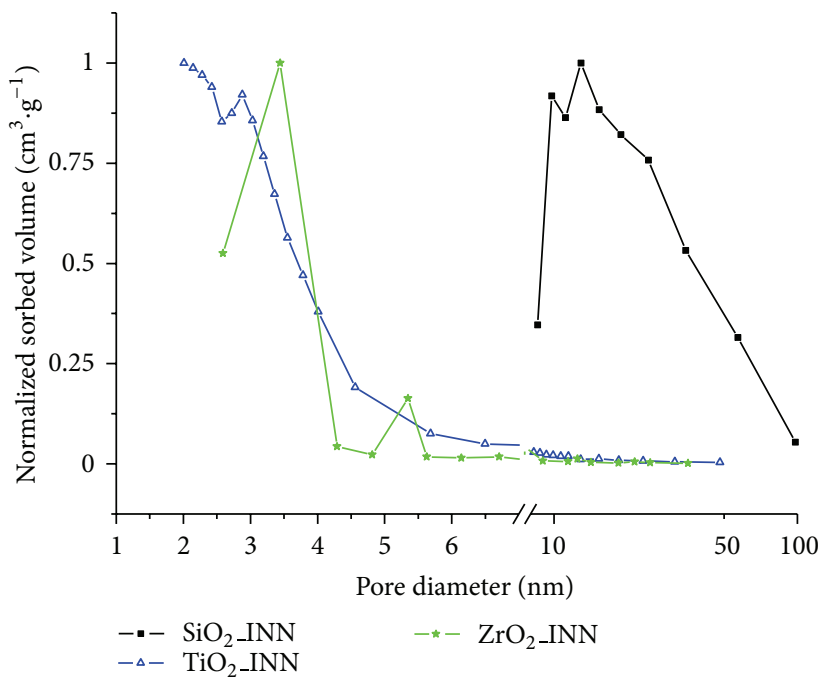

(b)

FIGURE 4: (a) Nitrogen sorption isotherms and (b) BJH pore size distribution (on the abscissa axis: linear scale before the break and $\log$ scale after the break) of various INNs (black squares for $\mathrm{SiO}_{2} \mathrm{INN}$, blue triangles for $\mathrm{TiO}_{2} \mathrm{INN}$, and green stars for $\mathrm{ZrO}_{2}$ INN).

of $13.1 \mathrm{~nm}$, a distance of $13.8 \mathrm{~nm}$, and relatively high packing density (hard sphere volume ratio $\eta=0.17$ ). Therefore, the curvature of the nanoparticle is very low and the ligands are facing an almost plane surface. It follows that in $\mathbf{S i O}_{2}$ INN, the ligands can be organized between the nanoparticles. This short-range ordering of the ligands can be detected by the scattering peak observed around $5 \mathrm{~nm}^{-1}$ in the SAXS curve (Figure 3) [33]. The organized ligands between the nanoparticles are then building a relatively dense organic phase (size and distance $1.1 \mathrm{~nm}, \eta=0.18$ ) and preclude the formation of small cavities (Scheme 2, top left). The good networking is directly visible in Figure 3 by the relatively strong intensity of the peak corresponding to the silica nanoparticles at $0.4 \mathrm{~nm}^{-1}$ 


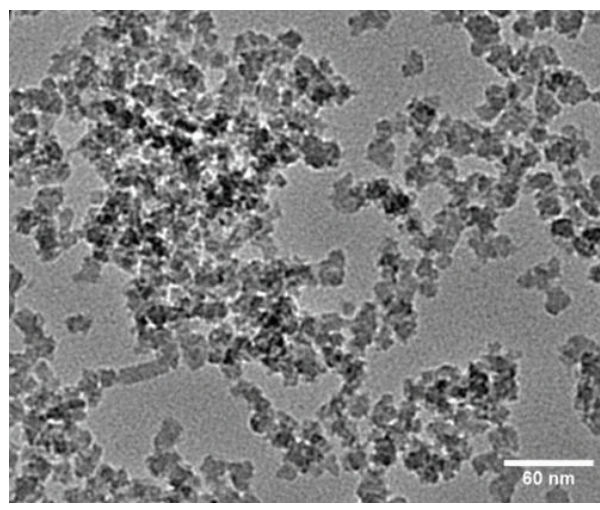

(a)

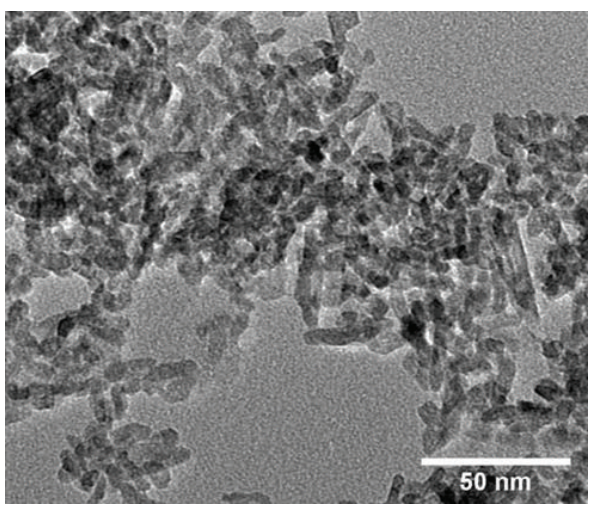

(b)

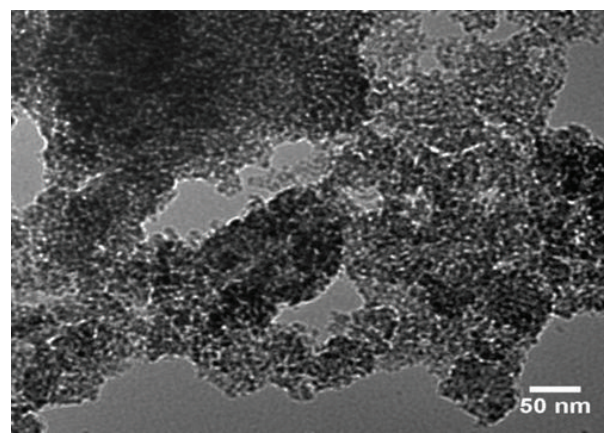

(c)

FIgURE 5: TEM micrographs of the Ionic Nanoparticle Networks (a) $\mathrm{SiO}_{2} \_\mathrm{INN}$, (b) $\mathrm{ZrO}_{2} \_\mathrm{INN}$, and (c) $\mathrm{TiO}_{2}$ INN.

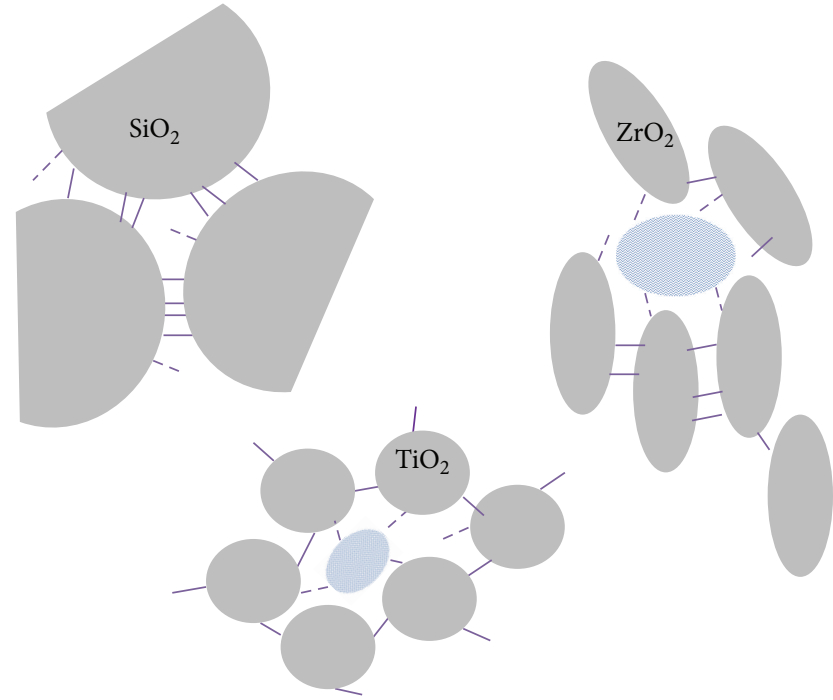

Scheme 2: Network porosity (striped circles) for (top left) $\mathrm{SiO}_{2}$ INN, (bottom centre) $\mathrm{TiO}_{2}$ INN, and (top right) $\mathrm{ZiO}_{2}$ INN.

(Figure 3) [26, 27]. The macropores, larger than $20 \mathrm{~nm}$, are formed in regions of the network where some ligands did not react.

In contrary to the titania nanoparticle networks TiO ${ }_{2}$ INN, the nanoparticles, $4 \mathrm{~nm}$ diameter, are small enough to present a strong curvature, with regard to the imidazolium ligands. Thus, more unreacted ligands could be observed, by means of solid-state ${ }^{15} \mathrm{~N}$ NMR where a clear peak for the imidazole could be observed at $131 \mathrm{ppm}$ next to the imidazolium peak at $142 \mathrm{ppm}$ [22]. The presence of these un-reacted ligands allows the formation of interparticle cavities having sizes slightly larger than the ionic liquid-like imidazolium bridging units (Scheme 2, bottom right). The SAXS intensity of $\mathbf{T i O}_{2}$ INN also highlights a more loose network with a broad size distribution, as a possible short range order peak at $2 \mathrm{~nm}^{-1}$ is weak (Figure 3) [22].

The case of $\mathbf{Z r O}_{2}$ INN is slightly different. Indeed, if the nanoparticles are of comparable size with the titania nanoparticles, they are not spherical any more but elongated (Figure 5(b)). It results in an overall better networking of the particles, revealed by a distinct short-range order peak of the zirconia nanoparticles at $1.0 \mathrm{~nm}^{-1}$ (Figure 3) with $\eta=0.08$.

The fit results in a typical particle diameter of $5.2 \mathrm{~nm}$, whereas the effective distance obtained from the structure factor is about $4.8 \mathrm{~nm}$ and therefore is slightly smaller than the spherical equivalent diameter of $5.2 \mathrm{~nm}$. This seems to be surprising, but a reasonable interpretation is that, on the one hand, the particles are elongated (TEM image, Figure 5(b)) and, on the other hand, the particles face mostly each other's long side. When two neighbouring nanoparticles are connected over a long face, similarly as for the silica nanoparticles, no space is left. But when two nanoparticles are connected by the shorter faces, mesopores can be formed in the nanoparticle interspace (Scheme 2, top right), somehow similarly as for titania nanoparticle-based materials. 


\section{Conclusion}

In this paper we have presented a new Ionic Nanoparticle Network (INN) based on zirconia nanoparticles linked by ionic liquid-like imidazolium bridging units. The porous characteristics of the new zirconia INN were compared to those of titania- and silica-based INN.

It was shown that the porous characteristics of the INN depend on the size and shape of the nanoparticles. INNs based on large spherical nanoparticles, like $\mathrm{SiO}_{2}$, are macroporous, while INNs based on small spherical nanoparticles, like $\mathrm{TiO}_{2}$, are microporous. The use of elongated small zirconia nanoparticles drives to the formation of a mesoporous hybrid material.

The porosity observed in the INN materials should ensure accessibility of the functional units for catalysis experiments.

\section{Conflict of Interests}

The authors declare having no direct financial relation with the trademarks mentioned in the paper.

\section{Acknowledgment}

This work was financially supported by the Austrian Fonds zur Förderung der Wissenschaftlichen Forschung (FWF, Project P21190-N17).

\section{References}

[1] Gacoin, Besson, and Boilot, "Organized mesoporous silica films as templates for the elaboration of organized nanoparticle networks," Journal of Physics Condensed Matter, vol. 18, no. 13, pp. S85-S95, 2006.

[2] S. Siavoshi, C. Yilmaz, S. Somu et al., "Size-selective templateassisted electrophoretic assembly of nanoparticles for biosensing applications," Langmuir, vol. 27, no. 11, pp. 7301-7306, 2011.

[3] B. Basnar, M. Litschauer, S. Abermann, E. Bertagnolli, G. Strasser, and M. A. Neouze, "Layer-by-layer assembly of titania nanoparticles based ionic networks," Chemical Communications, vol. 47, pp. 361-363, 2011.

[4] S. Easwaramoorthi, P. Kim, J. M. Lim et al., "The self-assembly and photophysical characterization of tri(cyclopenta[def] phenanthrene)-derived nanoparticles: a template free synthesis of hollow colloidosomes," Journal of Materials Chemistry, vol. 20, no. 43, pp. 9684-9694, 2010.

[5] D. Jańczewski, N. Tomczak, S. Liu, M. Han, and G. J. Vancso, "Covalent assembly of functional inorganic nanoparticles by "click" chemistry in water," Chemical Communications, vol. 46, no. 19, pp. 3253-3255, 2010.

[6] M. Litschauer and M. Neouze, "Nanoparticles connected through an ionic liquid-like network," Journal of Materials Chemistry, vol. 18, no. 6, pp. 640-646, 2008.

[7] M. A. Neouze, "About the interactions between nanoparticles and imidazolium moieties: emergence of original hybrid materials," Journal of Materials Chemistry, vol. 20, no. 43, pp. 9593-9607, 2010.

[8] L. Wang, J. Luo, M. J. Schadt, and C. Zhong, "Thin film assemblies of molecularly-linked metal nanoparticles and multifunctional properties," Langmuir, vol. 26, no. 2, pp. 618-632, 2010.
[9] K. Moller, B. Yilmaz, U. Muller, and T. Bein, "Hierarchical zeolite beta via nanoparticle assembly with a cationic polymer," Chemistry of Materials, vol. 23, no. 19, pp. 4301-4310, 2011.

[10] Q. Yao and S. L. Brock, "Porous CdTe nanocrystal assemblies: ligation effects on the gelation process and the properties of resultant aerogels," Inorganic Chemistry, vol. 50, no. 20, pp. 9985-9992, 2011.

[11] J. B. Wacker, V. K. Parashar, and M. A. M. Gijs, "Anisotropic magnetic porous assemblies of oxide nanoparticles interconnected via silica bridges for catalytic application," Langmuir, vol. 27, no. 8, pp. 4380-4385, 2011.

[12] M. R. Gao, S. R. Zhang, J. Jiang, Y. R. Zheng, D. Q. Tao, and S. H. Yu, "One-pot synthesis of hierarchical magnetite nanochain assemblies with complex building units and their application for water treatment," Journal of Materials Chemistry, vol. 21, no. 42, pp. 16888-16892, 2011.

[13] S. Chen, J. Zhang, T. Wu, P. Feng, and X. Bu, "Multiroute synthesis of porous anionic frameworks and size-tunable extraframework organic cation-controlled gas sorption properties," Journal of the American Chemical Society, vol. 131, no. 44, pp. 1602716029, 2009.

[14] R. S. Crees, M. L. Cole, L. R. Hanton, and C. J. Sumby, "Synthesis of a zinc(II) imidazolium dicarboxylate ligand metal-organic framework (MOF): a potential precursor to MOF-tethered Nheterocyclic carbene compounds," Inorganic Chemistry, vol. 49, no. 4, pp. 1712-1719, 2010.

[15] S. U. Hong, D. Park, Y. Ko, and I. Baek, "Polymer-ionic liquid gels for enhanced gas transport," Chemical Communications, no. 46, pp. 7227-7229, 2009.

[16] D. Kerlé, R. Ludwig, A. Geiger, and D. Paschek, “Temperature dependence of the solubility of carbon dioxide in imidazoliumbased ionic liquids," Journal of Physical Chemistry B, vol. 113, no. 38, pp. 12727-12735, 2009.

[17] A. Mavrandonakis, E. Klontzas, E. Tylianakis, and G. E. Froudakis, "Enhancement of hydrogen adsorption in metalorganic frameworks by the incorporation of the sulfonate group and Li cations. A Multiscale Computational Study," Journal of the American Chemical Society, vol. 131, no. 37, pp. 13410-13414, 2009.

[18] M. P. Stracke, G. Ebeling, R. Cataluña, and J. Dupont, "Hydrogen-storage materials based on imidazolium ionic liquids," Energy and Fuels, vol. 21, no. 3, pp. 1695-1698, 2007.

[19] A. Revelli, F. Mutelet, and J. Jaubert, "High carbon dioxide solubilities in imidazolium-based ionic liquids and in poly(ethylene glycol) dimethyl ether," Journal of Physical Chemistry B, vol. 114, no. 40, pp. 12908-12913, 2010.

[20] W. Shi and D. C. Sorescu, "Molecular simulations of $\mathrm{CO}_{2}$ and $\mathrm{H}_{2}$ sorption into ionic liquid 1- $\mathrm{n}$-hexyl-3-methylimidazolium bis(trifluoromethylsulfonyl)amide ([hmim][Tf2N]) confined in carbon nanotubes," Journal of Physical Chemistry B, vol. 114, no. 46, pp. 15029-15041, 2010.

[21] J. Y. Lee, J. M. Roberts, O. K. Farha, A. A. Sarjeant, K. A. Scheidt, and J. T. Hupp, "Synthesis and gas sorption properties of a Metal-Azolium Framework (MAF) material," Inorganic Chemistry, vol. 48, no. 21, pp. 9971-9973, 2009.

[22] M. A. Neouze, M. Litschauer, M. Puchberger, and H. Peterlik, "Porous titania ionic nanoparticle networks," Langmuir, vol. 27, no. 7, pp. 4110-4116, 2011.

[23] M. Neouze and U. Schubert, "Surface modification and functionalization of metal and metal oxide nanoparticles by organic ligands," Monatshefte fur Chemie, vol. 139, no. 3, pp. 183-195, 2008 . 
[24] M. Litschauer, M. Puchberger, H. Peterlik, and M. Neouze, "Anion metathesis in ionic silica nanoparticle networks," Journal of Materials Chemistry, vol. 20, no. 7, pp. 1269-1276, 2010.

[25] H. Friebolin, Basic One- and Two- Dimensional NMR Spectroscopy, Wiley-VCH, Weinheim, Germany, 4th edition, 2004.

[26] B. Feichtenschlager, S. Pabisch, H. Peterlik, and G. Kickelbick, "Nanoparticle assemblies as probes for self-assembled monolayer characterization: correlation between surface functionalization and agglomeration behavior," Langmuir, vol. 28, no. 1, pp. 741-750, 2012.

[27] S. Pabisch, B. Feichtenschlager, G. Kickelbick, and H. Peterlik, "Effect of interparticle interactions on size determination of zirconia and silica based systems-a comparison of SAXS, DLS, BET, XRD and TEM,' Chemical Physics Letters, vol. 521, pp. 9197, 2012.

[28] J. Brunner-Popela, R. Mittelbach, R. Strey, K. V. Schubert, E. W. Kaler, and O. Glatter, "Small-angle scattering of interacting particles. III. $\mathrm{D}_{2} \mathrm{O}-\mathrm{C}_{12} \mathrm{E}_{5}$ mixtures and microemulsions with noctane," Journal of Chemical Physics, vol. 110, no. 21, pp. 10623$10632,1999$.

[29] G. Beaucage, "Approximations leading to a unified exponential/power-law approach to small-angle scattering," Journal of Applied Crystallography, vol. 28, pp. 717-728, 1995.

[30] G. Beaucage and D. W. Schaefer, "Structural studies of complex systems using small-angle scattering: a unified Guinier/powerlaw approach," Journal of Non-Crystalline Solids, vol. 172, no. 2, pp. 797-805, 1994.

[31] D. J. Kinning and E. L. Thomas, "Hard-sphere interactions between spherical domains in diblock copolymers," Macromolecules, vol. 17, no. 9, pp. 1712-1718, 1984.

[32] F. Rouquerol, J. Rouquerol, and K. Sing, Adsorption by Powders and Porous Solids: Principles, Methodology and Applications, Academic Press, London, UK, 1999.

[33] M. Czakler, M. Litschauer, K. F. Föttinger, H. Peterlik, and M. A. Neouze, "Photoluminescence as complementary evidence for short-range order in ionic silica nanoparticle networks," The Journal of Physical Chemistry C, vol. 114, no. 49, pp. 21342-21347, 2010. 

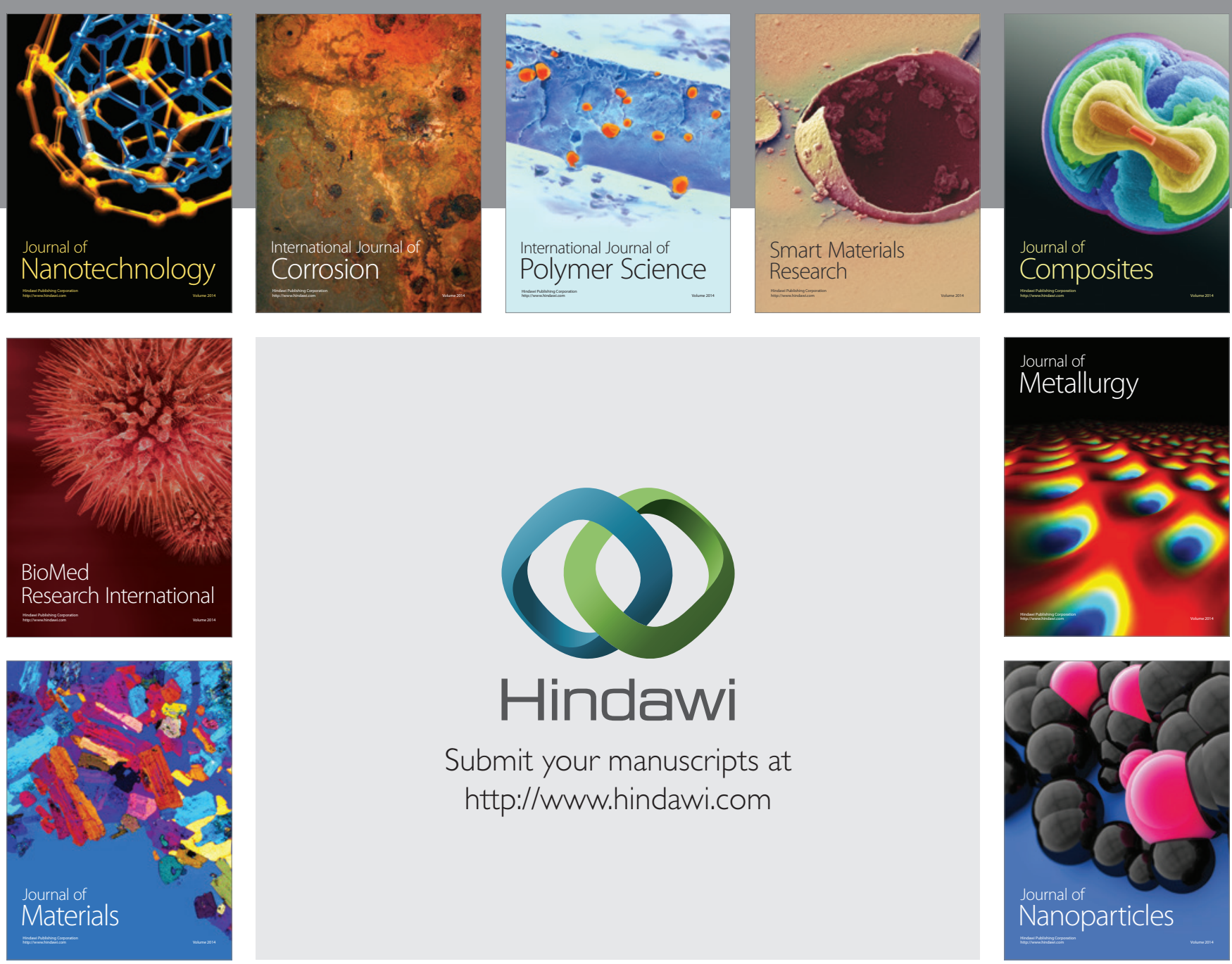

Submit your manuscripts at http://www.hindawi.com
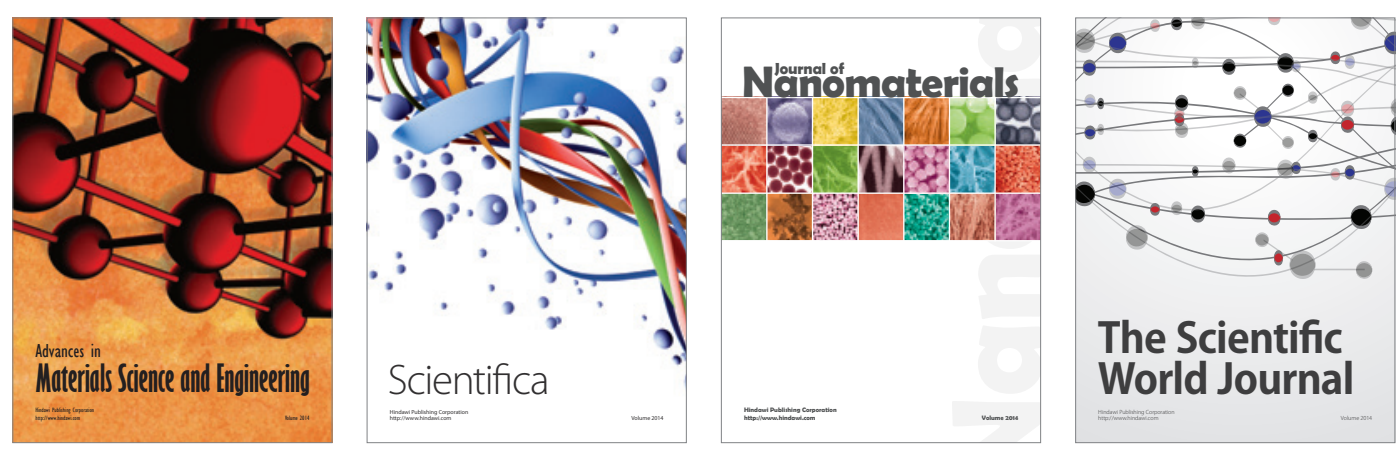

\section{The Scientific World Journal}
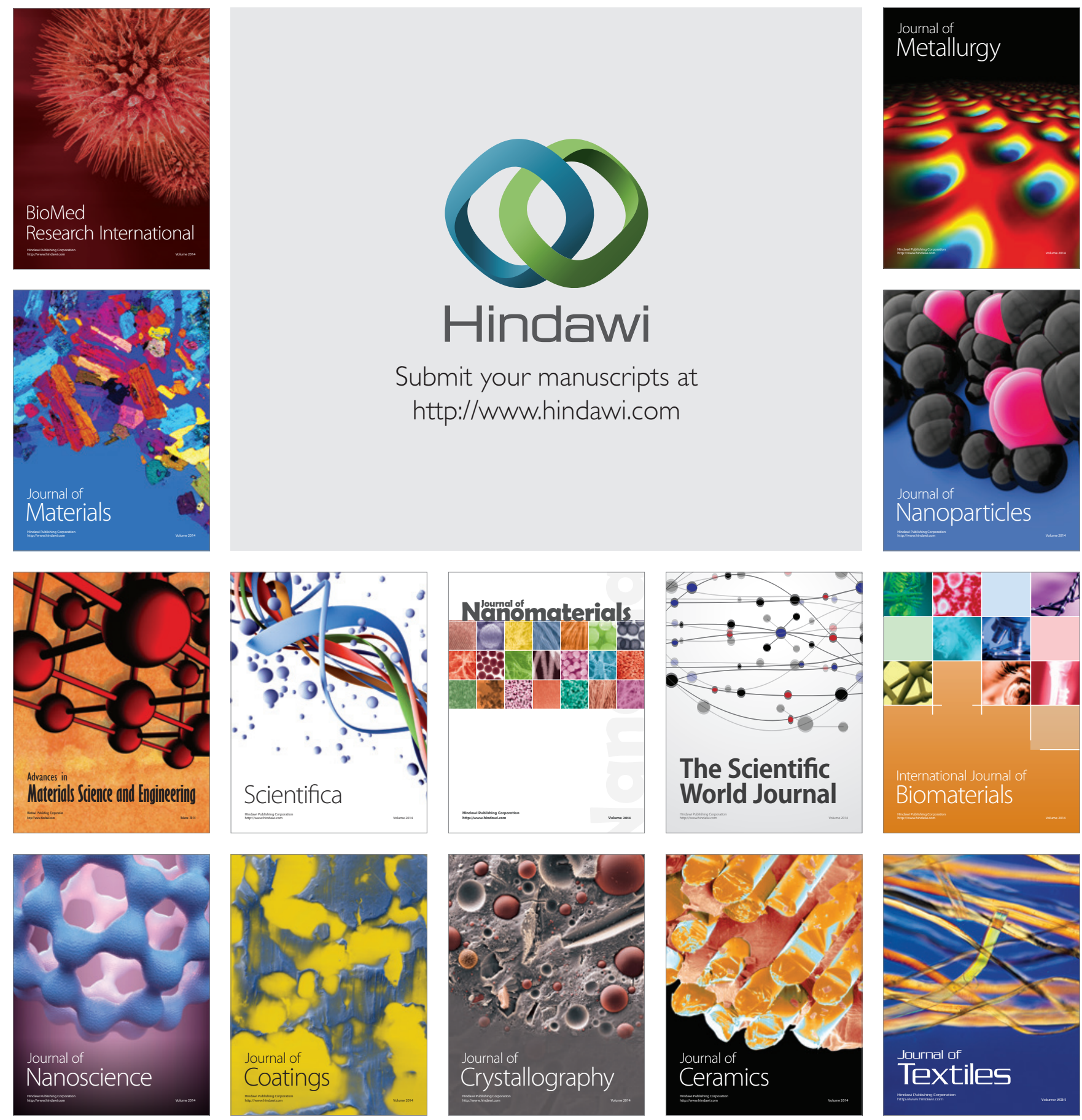